\title{
Orthodontic treatment need for adolescents in the Campania region: the malocclusion impact on self-concept
}

This article was published in the following Dove Press journal:

Patient Preference and Adherence

19 March 2014

Number of times this article has been viewed

\author{
Letizia Perillo' \\ Maria Esposito ${ }^{2}$ \\ Alberto Caprioglio 3 \\ Stefania Attanasio' \\ Annamaria Chiara Santini ${ }^{2}$ \\ Marco Carotenuto ${ }^{2}$ \\ 'Department of Orthodontics, Second \\ University of Naples, Naples, Italy; \\ ${ }^{2}$ Clinic of Child and Adolescent \\ Neuropsychiatry, Department of \\ Mental Health, Physical and Preventive \\ Medicine, Second University of \\ Naples, Naples, Italy; ${ }^{3}$ Department of \\ Orthodontics, University of Insubria, \\ Varese, Italy
}

Background: Dental malocclusions can be considered not only as an oral health problem, because they are linked to quality of life perception. Many factors related to malocclusion have strong influences on the perception of facial esthetics (eg, anterior tooth alignment, tooth shape and position, lip thickness, symmetric gingival or tooth contour, lip profile, and overjet). Many reports have shown that the perception of facial esthetics can influence psychological development from early childhood to adulthood. The aim of this study is to investigate the effect of dental malocclusion on self-esteem in a sample of adolescents.

Materials and methods: The study population was composed of 516 orthodontically untreated subjects (256 males) mean ages 13.75 \pm 1.977 years recruited from schools in the Campania region of Italy between January 2011 and July 2011. To evaluate the self-esteem grade in our population, all subjects filled out the Multidimensional Self Concept Scale questionnaire and attended an orthodontic clinical evaluation to estimate dental occlusal aspects.

Results: Pearson's analysis shows the relationship in our sample between some occlusal characteristics (crossbite and dental crowding) and aspects of self-concept evaluation (social, competence, academic, physical, and global score) of the Multidimensional Self Concept Scale questionnaire. Moreover, logistic regression analysis shows the potential role of dental crowding (odds ratio 5.359; 95\% confidence interval 3.492-8.225) and crossbite (odds ratio 6.153; 95\% confidence interval 3.545-10.678) as risk factors for development of global self-concept score abnormalities.

Conclusion: Our findings confirm the relationship between psychosocial well-being, selfesteem, and dental malocclusion among adolescents.

Keywords: dental malocclusion, self-concept, adolescents, crossbite, dental crowding

\section{Introduction}

Physical appearance seems to play a key role in self-esteem ${ }^{1,2}$ in all epochs of life. In pediatric age, body self-image could be altered and undermined by physical illness ${ }^{3-5}$ and by malocclusion, with great impact on all aspects of life, such as socialization, emotional and functional aspects of life, and familiar inter-relationships, ${ }^{6-10}$ and also between the ages of 8 and 10 years. ${ }^{10}$ Malocclusions and altered dentofacial esthetics often do not compromise oral function but can influence a person's body image formation, emotional development, self-esteem, and social integration worldwide. ${ }^{11-14}$

In this light, malocclusion may be considered not only as an oral health problem, because it is linked to general quality of life, even if the relationship between emotional and/or social well-being and malocclusions is still not clarified or widely considered in the clinical literature. Moreover, improvement in esthetic satisfaction due to the
Correspondence: Marco Carotenuto Clinic of Child and Adolescent Neuropsychiatry, Department of Mental Health, Physical and Preventive Medicine, Second University of Naples, Via Sergio Pansini, 5, 80131, Napoli, Italy

Tel +39815666988

Fax +39 8I 5666694

Email marco.carotenuto@unina2.it 
treatment of severe malocclusion improves oral health-related quality of life, particularly by decreasing psychological discomfort and psychological disability. ${ }^{15}$

On the other hand, facial esthetic alterations can impact general well-being perception, as shown in young adults presenting severe malocclusion, ${ }^{16}$ suggesting the need for seeking orthodontic treatment in order to improve personal appearance. ${ }^{17,18}$

Alternatively, many other factors related to malocclusion seem to have strong influences on the perception of facial esthetics, as reported by many studies about the effects of anterior tooth alignment, tooth shape and position, lip thickness, symmetric gingival or tooth contour, lip profile, and overjet. ${ }^{19-21}$

Moreover, Badran ${ }^{22}$ reported in 2010 the effect of physical appearance on self-concept and social acceptance, showing that students who had a need for orthodontic treatment demonstrated a lower self-esteem than those with little or no need for orthodontic treatment.

Finally, the specific relationship between malocclusion and emotional and social well-being has not yet been clarified. Therefore, the aim of the present study was to investigate the effect of dental malocclusion on self-concept in a sample of adolescents.

\section{Subjects and methods Study population}

The study population was composed of 516 orthodontically untreated subjects (256 males) with a mean age of $13.75 \pm 1.977$ years, recruited from schools in the Campania region of Italy. Students with craniofacial abnormalities or who had already finished their orthodontic treatment and those who were undergoing treatment at the time of the study were excluded. Other exclusion criteria were the following: genetic syndromes, ${ }^{23-26}$ allergies, endocrinological problems (eg, diabetes), preterm birth, ${ }^{27,28}$ neurological (eg, epilepsy, primary headaches) $)^{29-40}$ or psychiatric symptoms (attention-deficit/ hyperactivity disorder, depression, behavioral problems), mental retardation (intelligence quotient $[\mathrm{IQ}] \leq 70$ ), borderline intellectual functioning (IQ ranging from 71 to 84 ), ${ }^{41,42}$ overweight (body mass index $\geq 85$ th percentile) or obesity (body mass index $\geq 95$ th percentile), ${ }^{43,44}$ sleep disorders, ${ }^{45-51}$ primary nocturnal enuresis or encopresis, ${ }^{52-55}$ and anticonvulsant ${ }^{56-58}$ or psychoactive drug administration.

To evaluate the self-esteem rate in our population, all subjects filled out the Italian version of the Multidimensional Self Concept Scale (MSCS) questionnaire, ${ }^{59,60}$ and an orthodontic clinical evaluation to estimate the dental occlusal aspects was performed.
All the subjects were recruited from the same urban area, were all Caucasian, and held a middle-class socioeconomic status (between class II or class III, corresponding to $28,000-55,000$ euros/year to 55,000-75,000 euros/year, respectively, according to the current Italian economic legislation parameters) as previously reported. ${ }^{4-7}$

All parents gave their written informed consent. The Departmental Ethics Committee at the Second University of Naples, Naples, Italy, approved the study. The study was conducted according to the criteria of the Declaration of Helsinki. ${ }^{61}$

\section{Multidimensional Self Concept Scale}

As reported in a previous study, ${ }^{4}$ the Italian version of the MSCS $^{60,61}$ was used to measure global self-concept and six specific domains of self-concept: social, competence, affect, academic, family, and physical. Each domain consists of 25 items. Each item ranged from 1 (strongly agree) to 4 (strongly disagree). Negatively worded items were reverse scored. The raw global score and domain scores were calculated as sums of all items or of domain-specific items. The global and domain scores were then standardized (IQ metric) using the standard score conversions available in the user manual. A higher score indicates a more positive self-concept.

The MSCS was used to assess global and domain-specific self-concepts. The MSCS is a 150-item self-report inventory appropriate for either individual or group administration to youth between the ages of 9 and 19 years, inclusive. The MSCS provides a total scale score, as well as standard scores $($ mean $=100$; standard deviation $=15$ ) for each of six domain-specific scales (ie, social, competence, affect, academic, family, and physical). The MSCS is based on a more comprehensive context-dependent, multidimensional model of social emotional adjustment and assessment. Consistent with other self-concept measures, the MSCS appears to assess a robust construct that is fairly invariant across various demographic variables.

For the Italian MSCS version, the total scale internal consistency was 0.98 for the entire scale, and for the six scales ranged from 0.87 to 0.97 .

\section{Orthodontic clinical examination}

As previously reported, ${ }^{62-65}$ characteristics of dental occlusion were studied using latex gloves, dental mouth mirrors, and millimetric rulers. No radiographs, study casts, or previous written records were used. Personal data and information about orthodontic treatment were obtained from each subject. The examination lasted approximately 15 minutes per child, according to World Health Organization (1985) guidelines. ${ }^{66}$ 
The orthodontic examinations included molar relationship, posterior crossbite or scissor bite, overjet and overbite, crowding, and diastemas.

\section{Molar relationship}

The relationship between the upper and lower first permanent molars was determined according to Angle's classification, as reported by Perillo et al. ${ }^{62}$ Patients with subdivision malocclusions were included in the class II or class III groups on the basis of the predominant occlusal characteristic, or according to the relationship between the canines.

\section{Overjet and overbite}

Values between $0 \mathrm{~mm}$ and $4 \mathrm{~mm}$ were considered normal.

\section{Posterior crossbite}

A posterior crossbite was diagnosed when there was a crossover of at least one tooth in the posterior segments of the dental arches. A posterior crossbite could be unilateral (right or left) or bilateral.

\section{Scissor bite}

A scissor bite was considered to be present when the palatal cusps of the upper molars were positioned buccally in relation to the buccal cusps of the lower molars.

\section{Crowding and diastemas}

These were recorded for the anterior as well as for the posterior segments. A midline diastema was considered to be present when there was a space of at least $2 \mathrm{~mm}$ between the maxillary central incisors.

\section{Statistical analysis}

In order to evaluate the correlation between occlusal characteristics and global and domain-specific self-concept derived from the MSCS questionnaire, the Pearson's correlation test was applied. The Student's $t$-test was performed in order to compare the mean values of global and domain-specific selfconcept score between children with and without dental crowding and crossbite, respectively. Chi-square test was used for the comparison of sex distribution in the examined groups.

For all statistical analysis, significant $P$-values $<0.05$ were considered. Moreover, in order to improve the statistical significance, the Bonferroni $P$ corrected values were obtained. All data were coded and analyzed using the commercially available STATISTICA 6.0 package for Windows (StatSoft, Inc., Tulsa, OK, USA). Then, the role as risk factors of dental crowding and crossbite in development of selfesteem abnormalities, scored from MSCS global self-concept value, was estimated using 95\% confidence intervals (CI) of odds ratio (OR) calculations with online software (http:// www.hutchon.net/ConfidOR.htm).

\section{Results}

Table 1 shows the Pearson's analysis results between crossbite, dental crowding, and self-concept evaluation findings (social, competence, affect, academic, physical, and global score) according to MSCS questionnaire (Table 1).

Table 2 shows a statistically significant reduction in MSCS mean values of children with dental crowding in respect of children without this disturbance; moreover, children with dental crowding show mean values in the pathological range $(\leq 86)$ for social $(P<0.001)$, competence $(P<0.001)$, physical $(P<0.001)$, and global score $(P<0.001)$ of MSCS (Table 2).

Table 3 shows the results of self-concept evaluation (MSCS score values) in children with crossbite compared with children without crossbite. In these subjects, the values of MSCS score were significantly lower than children without crossbite and were in the pathological range $(\leq 86)$ for social

Table I Pearson's correlation values between dental occlusion characteristics and specific domains of self-concept according to Multidimensional Self Concept Scale parameters

\begin{tabular}{|c|c|c|c|c|c|c|c|}
\hline & Social & Competence & Affect & Academic & Family & Physical & Global score \\
\hline Class I & 0.02 & 0.02 & -0.05 & -0.02 & -0.04 & 0.04 & 0.01 \\
\hline Class II & 0.03 & 0.00 & 0.05 & 0.04 & 0.06 & -0.02 & 0.02 \\
\hline Class III & -0.10 & -0.04 & 0.01 & -0.04 & -0.04 & -0.05 & -0.07 \\
\hline Crossbite & $-0.48^{\mathrm{a}, \mathrm{b}}$ & $-\left.0.3\right|^{a, b}$ & 0.00 & $-0.14^{\mathrm{a}}$ & -0.10 & $-0.39^{a, b}$ & $-\left.0.4\right|^{a, b}$ \\
\hline Scissor bite & -0.01 & 0.07 & 0.09 & 0.12 & $0.13^{\mathrm{a}}$ & 0.02 & 0.04 \\
\hline Overbite & -0.01 & 0.01 & 0.02 & 0.09 & 0.07 & -0.02 & 0.02 \\
\hline Overjet & 0.10 & 0.10 & 0.00 & $0.13^{a}$ & 0.08 & 0.07 & 0.11 \\
\hline Dental crowding & $-\left.0.5\right|^{\mathrm{a}, \mathrm{b}}$ & $-0.54^{\mathrm{a}, \mathrm{b}}$ & $-0.28^{\mathrm{a}, \mathrm{b}}$ & $-0.22^{\mathrm{a}, \mathrm{b}}$ & $-0.15^{\mathrm{a}}$ & $-0.47^{\mathrm{a}, \mathrm{b}}$ & $-0.52^{\mathrm{a}, \mathrm{b}}$ \\
\hline Diastemas & 0.10 & 0.12 & $0.15^{\mathrm{a}}$ & 0.10 & 0.10 & 0.07 & 0.09 \\
\hline
\end{tabular}

Notes: a ${ }^{2}$ alues were statistically significant $(P \leq 0.05)$; ${ }^{b} P$-values $\leq 0.00$ I. 
Table 2 Comparison of mean distribution in specific domain and global score of Multidimensional Self Concept Scale between subjects with dental crowding and subjects without dental crowding

\begin{tabular}{|c|c|c|c|}
\hline & $\begin{array}{l}\text { Dental } \\
\text { crowding } \\
(\mathrm{N}=\mathbf{2 2 2})\end{array}$ & $\begin{array}{l}\text { No dental } \\
\text { crowding } \\
(\mathrm{N}=294)\end{array}$ & $P^{a}$ \\
\hline Sex (male/female) & $110 / 112$ & $|46 /| 48$ & NS \\
\hline Age & $13.959 \pm 2.174$ & $|3.59| \pm \mid .802$ & NS \\
\hline Social & $78.455 \pm 22.550$ & $99.408 \pm|8.35|$ & $<0.001$ \\
\hline Competence & $76.648 \pm 21.786$ & $96.653 \pm 15.280$ & $<0.001$ \\
\hline Affect & $94.162 \pm 13.035$ & $99.959 \pm 10.907$ & $<0.001$ \\
\hline Academic & $93.464 \pm 10.582$ & $96.803 \pm 13.708$ & 0.021 \\
\hline Family & $99.108 \pm 11.008$ & $100.398 \pm 10.240$ & NS \\
\hline Physical & $77.428 \pm 24.769$ & $96.949 \pm 16.512$ & $<0.001$ \\
\hline Global score & $80.459 \pm 19.805$ & $97.646 \pm|4.83|$ & $<0.001$ \\
\hline
\end{tabular}

Notes: ap-value $\leq 0.05$ was considered statistically significant. Bonferroni corrected values. The data in the Dental crowding and No dental crowding columns are shown as mean \pm standard deviation.

Abbreviation: NS, not significant.

$(P<0.001)$, competence $(P<0.001)$, academic $(P=0.019)$, physical $(P<0.001)$, and global score $(P<0.001)$.

Finally, odds ratio analysis shows the potential role of dental crowding (OR $=5.359 ; 95 \%$ CI 3.492-8.225) and crossbite $(\mathrm{OR}=6.153 ; 95 \% \mathrm{CI} 3.545-10.678)$ as risk factors for development of global self-concept score abnormalities.

\section{Discussion}

The main findings of our study could be summarized with the higher prevalence of low self-concept in adolescents with dental malocclusion, representing a significant risk factor for global dissatisfaction. On the other hand, esthetics can be defined as relating to feeling independent from an educational level, ${ }^{67}$ and the perception can be defined as the organization

Table 3 Comparison of mean distribution in specific domain and global score of Multidimensional Self Concept Scale between subjects with crossbite and subjects without crossbite

\begin{tabular}{llll}
\hline & $\begin{array}{l}\text { Crossbite } \\
(\mathbf{N}=65)\end{array}$ & $\begin{array}{l}\text { No crossbite } \\
\mathbf{( N = 4 5 I )}\end{array}$ & $\boldsymbol{P}^{\mathbf{a}}$ \\
\hline Sex (male/female) & $31 / 34$ & $225 / 226$ & $\mathrm{NS}$ \\
Age & $13.819 \pm 1.412$ & $13.656 \pm 1.902$ & $\mathrm{NS}$ \\
Social & $64.415 \pm 26.970$ & $94.137 \pm 19.428$ & $<0.00 \mathrm{I}$ \\
Competence & $72.092 \pm 20.685$ & $90.346 \pm 19.867$ & $<0.00 \mathrm{I}$ \\
Affect & $95.938 \pm 13.624$ & $97.685 \pm 11.982$ & $\mathrm{NS}$ \\
Academic & $90.954 \pm 11.108$ & $96.002 \pm 12.638$ & 0.019 \\
Family & $97.000 \pm 9.520$ & $100.253 \pm 10.678$ & $\mathrm{NS}$ \\
Physical & $67.031 \pm 23.559$ & $91.652 \pm 20.748$ & $<0.00 \mathrm{I}$ \\
Global score & $71.062 \pm 21.568$ & $93.018 \pm 17.084$ & $<0.00 \mathrm{I}$ \\
\hline
\end{tabular}

Notes: a $P$-value $\leq 0.05$ was considered statistically significant. Bonferroni corrected values. The data in the Crossbite and No crossbite columns are shown as mean \pm standard deviation.

Abbreviation: NS, not significant. of environmental stimuli. Therefore, various physical, psychological, and social factors that affect perceptual judgments are described and relate to the development and maintenance of self-image and/or concept. ${ }^{68}$ In fact, generally, orthodontic treatment is normally requested for cosmetic need, and dentofacial problems causing cosmetic impairment can be considered as detrimental because of their adverse effect on an adolescent's self-esteem ${ }^{69}$ and possible unfavorable social responses. ${ }^{70}$ In this perspective, our findings about the presence of self-esteem pathological scores in subjects with dental crowding and those with crossbite could be interpreted (Tables 2 and 3).

Alternatively, the relationship between physical appearance and perception of an esthetic deviation and the impact of such a deviation on self-esteem and body image can be considered as an important issue for determining the benefits and outcomes of orthodontic treatment that are also largely determined by biological and psychological factors. ${ }^{71}$

Anyway, several social, cultural and psychological factors, and personal norms can influence the perception of physical attractiveness. ${ }^{72,73}$ In general, high income social class individuals are considered to be more critical, whereas younger children are usually less aware of their dental appearance, ${ }^{72}$ even if adolescents reported similar perceptions of malocclusion irrespective of sex or social background, when scored by an examiner as having similar dental esthetics. ${ }^{74}$

In fact, studies in social psychology suggest the key role of physical attractiveness also for social interaction influencing the perception of an individual's social skill. ${ }^{75,76}$ In this point of view, we could explain our results about the apparently simultaneous pathological reduction in self-concept score of social and physical domain for subjects with dental crowding (social 78.455 \pm 22.55 ; physical 77.428 \pm 24.769 , respectively) such as among subjects with crossbite (social 64.415 \pm 26.970 ; physical 67.031 \pm 23.559 , respectively).

Moreover, Trulsson et al ${ }^{77}$ have suggested that 14 to 17 -year-old youths could be identified as the most vulnerable, with regard to psychological well-being and higher levels of pain during the phases of orthodontic treatment. Recently, Peres et a $\mathrm{l}^{78}$ have suggested that adolescents reported pleasant esthetics as an important factor for psychosocial well-being and, in general, that orthodontic treatment is accepted as an important part of the health service, especially due to the psychological impact of malocclusion on self-esteem.

Conversely, our findings tend to confirm this relationship between psychosocial well-being, self-esteem, and dental malocclusion among adolescents, as pinpointed by the lower score in more self-esteem domains (social, competence, physical, and global scores) of subjects with dental crowding and 
crossbite $(P<0.001$ for all variables). In addition, considering that the appearance of the mouth and the smile plays an important role in other people's judgment of facial attractiveness, ${ }^{79}$ we could explain the role as risk factors for development of low self-esteem of abnormalities of anterior occlusion such as dental crowding and posterior crossbite, as shown in our results (respectively OR $=5.359 ; 95 \%$ CI 3.492-8.225 and OR $=6.153 ; 95 \%$ CI 3.545-10.678). Moreover, previous surveys have showed that most people believe dental appearance to be important in social interactions. ${ }^{80,81}$ However, the impact of dental or peri-oral appearance differs among various sex and age groups.

Conversely, adolescent girls seem to perceive dental appearance as the more important characteristic, with maxillary anterior crowding having a greater influence than protrusion, as suggested also by a recent report. ${ }^{82}$ Undoubtedly, malocclusion has a psychological impact in adolescents, related to the severity of malocclusion, but without influence of social class. ${ }^{82}$

Finally, body image quality of life was affected not only by specific pathologies related to body image disturbances ${ }^{83}$ but also by orthodontic impairment such as malocclusion. Alternatively, orthodontists traditionally consider restored oral health, function, and esthetics as the principal therapeutic goals. ${ }^{84}$ However, improved esthetics and its positive psychosocial impact are increasingly being accepted as important benefits of treatment. ${ }^{85}$

We have to take into account two significant limitations for the present study: the lack of a control group of adolescents without dental malocclusion and the lack of orthodontic follow-up. Notwithstanding these limitations, our findings pinpoint that dental malocclusion can impact adolescent selfesteem and social contacts, consequently impairing all aspects of quality of life, suggesting the importance of more attention to patients' psychological aspects for correct treatment.

\section{Disclosure}

The authors report no conflicts of interest in this work.

\section{References}

1. Sousa Dias N, Tsingene F. SAEF - Smile's Aesthetic Evaluation Form: a useful tool to improve communications between clinicians and patients during multidisciplinary treatment. Eur J Esthet Dent. 2011;6(2):160-176.

2. Koronczai B, Kökönyei G, Urbán R, et al. The mediating effect of self-esteem, depression and anxiety between satisfaction with body appearance and problematic internet use. Am J Drug Alcohol Abuse. 2013;39(4):259-265.

3. Ferro MA, Boyle MH. Self-concept among youth with a chronic illness: a meta-analytic review. Health Psychol. 2013;32(8):839-848.

4. Esposito M, Gallai B, Parisi L, et al. Self-concept in childhood migraine. Neuropsychiatr Dis Treat. 2013;9:1061-1066.
5. Esposito M, Marotta R, Gallai B, et al. Temperamental characteristics in childhood migraine without aura: a multicenter study. Neuropsychiatr Dis Treat. 2013;9:1187-1192.

6. Esposito M, Gallai B, Parisi L, et al. Maternal stress and childhood migraine: a new perspective on management. Neuropsychiatr Dis Treat. 2013;9:351-355.

7. Carotenuto M, Esposito M, Di Pasquale F, De Stefano S, Santamaria F. Psychological, cognitive and maternal stress assessment in children with primary ciliary dyskinesia. World J Pediatr. 2013;9(4): 312-317.

8. Esposito M, Parisi L, Gallai B, et al. Attachment styles in children affected by migraine without aura. Neuropsychiatr Dis Treat. 2013;9: $1513-1519$.

9. Esposito M, Roccella M, Gallai B, et al. Maternal personality profile of children affected by migraine. Neuropsychiatr Dis Treat. 2013;9: 1351-1358.

10. Martins-Júnior PA, Marques LS, Ramos-Jorge ML. Malocclusion: social, functional and emotional influence on children. J Clin Pediatr Dent. 2012;37(1):103-108.

11. Tsakos G. Combining normative and psychosocial perceptions for assessing orthodontic treatment needs. J Dent Educ. 2008;72(8): 876-885.

12. Kolawole KA, Ayeni OO, Osiatuma VI. Psychosocial impact of dental aesthetics among university undergraduates. Int Orthod. 2012;10(1):96-109.

13. Onyeaso CO, Sanu OO. Perception of personal dental appearance in Nigerian adolescents. Am J Orthod Dentofacial Orthop. 2005;127(6): 700-706.

14. Seehra J, Fleming PS, Newton T, et al. Bullying in orthodontic patients and its relationship to malocclusion, self-esteem and oral health-related quality of life. J Orthod. 2011;38(4):247-256.

15. Silvola AS, Varimo M, Tolvanen M, et al. Dental esthetics and quality of life in adults with severe malocclusion before and after treatment. Angle Orthod. Epub December 5, 2013.

16. Claudino D, Traebert J. Malocclusion, dental aesthetic self-perception and quality of life in a 18 to 21 year-old population: a cross section study. BMC Oral Health. 2013;13:3.

17. Kiyak HA. Does orthodontic treatment affect patients' quality of life? J Dent Educ. 2008;72(8):886-894.

18. Kiyak HA. Cultural and psychologic influences on treatment demand. Semin Orthod. 2000;6(4):242-248.

19. Onyeaso CO. An assessment of relationship between self-esteem, orthodontic concern, and Dental Aesthetic Index (DAI) scores among secondary school students in Ibadan, Nigeria. Int Dent J. 2003;53(2): $79-84$.

20. Jung MH. Evaluation of the effects of malocclusion and orthodontic treatment on self-esteem in an adolescent population. Am J Orthod Dentofacial Orthop. 2010;138(2):160-166.

21. Albino JE, Alley TR, Tedesco LA, et al. Esthetic issues in behavioral dentistry. Ann Behav Med. 1990;12:148-155.

22. Badran SA. The effect of malocclusion and self-perceived aesthetics on the self-esteem of a sample of Jordanian adolescents. Eur J Orthod. 2010;32(6):638-644.

23. Carotenuto M, Esposito M, D'Aniello A, et al. Polysomnographic findings in Rett syndrome: a case-control study. Sleep Breath. 2013;17(1):93-98. Erratum in: Sleep Breath. 2013;17(2):877-878.

24. Elia M, Falco M, Ferri R, et al. CDKL5 mutations in boys with severe encephalopathy and early-onset intractable epilepsy. Neurology. 2008;71(13):997-999.

25. Elia M, Amato C, Bottitta M, et al. An atypical patient with Cowden syndrome and PTEN gene mutation presenting with cortical malformation and focal epilepsy. Brain Dev. 2012;34(10):873-876.

26. Parisi L, Di Filippo T, La Grutta S, et al. Sturge-Weber syndrome: a report of 14 cases. Mental Illness. 2013;5(e7):26-28.

27. Guzzetta A, Pizzardi A, Belmonti V, et al. Hand movements at 3 months predict later hemiplegia in term infants with neonatal cerebral infarction. Dev Med Child Neurol. 2010;52(8):767-772. 
28. Guzzetta A, D'Acunto MG, Carotenuto M, et al. The effects of preterm infant massage on brain electrical activity. Dev Med Child Neurol. 2011;53 Suppl 4:46-51.

29. Gallelli L, Avenoso T, Falcone D, et al. Effects of acetaminophen and ibuprofen in children with migraine receiving preventive treatment with magnesium. Headache. 2014;54(2):313-324.

30. Bellini B, Arruda M, Cescut A, et al. Headache and comorbidity in children and adolescents. J Headache Pain. 2013;14(1):79.

31. Esposito M, Ruberto M, Gimigliano F, et al. Effectiveness and safety of Nintendo Wii Fit Plus ${ }^{\mathrm{TM}}$ training in children with migraine without aura: a preliminary study. Neuropsychiatr Dis Treat. 2013;9:1803-1810.

32. Verrotti A, Agostinelli S, D'Egidio C, et al. Impact of a weight loss program on migraine in obese adolescents. Eur J Neurol. 2013;20: 394-397.

33. Esposito M, Ruberto M, Pascotto A, Carotenuto M. Nutraceutical preparations in childhood migraine prophylaxis: effects on headache outcomes including disability and behaviour. Neurol Sci. 2012;33:1365-1368.

34. Esposito M, Carotenuto M. Ginkgolide B complex efficacy for brief prophylaxis of migraine in school-aged children: an open-label study. Neurol Sci. 2011;32:79-81.

35. Carotenuto M, Esposito M. Nutraceuticals safety and efficacy in migraine without aura in a population of children affected by neurofibromatosis type I. Neurol Sci. 2013;34(11):1905-1909.

36. Esposito M, Pascotto A, Gallai B, et al. Can headache impair intellectual abilities in children? An observational study. Neuropsychiatr Dis Treat. 2012;8:509-513.

37. Esposito M, Verrotti A, Gimigliano F, et al. Motor coordination impairment and migraine in children: a new comorbidity? Eur J Pediatr. 2012;171(11):1599-1604

38. Carotenuto M, Esposito M, Precenzano F, et al. Cosleeping in childhood migraine. Minerva Pediatr. 2011;63(2):105-109.

39. Carotenuto M, Esposito M, Pascotto A. Migraine and enuresis in children: an unusual correlation? Med Hypotheses. 2010;75(1):120-122.

40. Esposito M, Roccella M, Parisi L, et al. Hypersomnia in children affected by migraine without aura: a questionnaire-based case-control study. Neuropsychiatr Dis Treat. 2013;9:289-294.

41. Esposito M, Carotenuto M. Intellectual disabilities and power spectra analysis during sleep: a new perspective on borderline intellectual functioning. J Intellect Disabil Res. Epub 2013 Mar 21.

42. Esposito M, Carotenuto M. Borderline intellectual functioning and sleep: the role of cyclic alternating pattern. Neurosci Lett. 2010;19;485(2): 89-93.

43. Carotenuto M, Santoro N, Grandone A, et al. The insulin gene variable number of tandem repeats (INS VNTR) genotype and sleep disordered breathing in childhood obesity. J Endocrinol Invest. 2009;32(9): 752-755.

44. Carotenuto M, Bruni O, Santoro N, et al. Waist circumference predicts the occurrence of sleep-disordered breathing in obese children and adolescents: a questionnaire-based study. Sleep Med. 2006;7(4): 357-361.

45. Carotenuto M, Guidetti V, Ruju F, et al. Headache disorders as risk factors for sleep disturbances in school aged children. $J$ Headache Pain. 2005;6(4):268-270.

46. Esposito M, Antinolfi L, Gallai B, et al. Executive dysfunction in children affected by obstructive sleep apnea syndrome: an observational study. Neuropsychiatr Dis Treat. 2013;9:1087-1094.

47. Carotenuto M, Gallai B, Parisi L, et al. Acupressure therapy for insomnia in adolescents: a polysomnographic study. Neuropsychiatr Dis Treat. 2013;9:157-162.

48. Esposito M, Parisi P, Miano S, et al. Migraine and periodic limb movement disorders in sleep in children: a preliminary case-control study. $J$ Headache Pain. 2013;14(1):57.

49. Carotenuto M, Gimigliano F, Fiordelisi G, et al. Positional abnormalities during sleep in children affected by obstructive sleep apnea syndrome: the putative role of kinetic muscular chains. Med Hypotheses. 2013;81(2):306-308.

50. Carotenuto M, Esposito M, Parisi L, et al. Depressive symptoms and childhood sleep apnea syndrome. Neuropsychiatr Dis Treat. 2012;8: 369-373.
51. Carotenuto M, Esposito M, Pascotto A. Facial patterns and primary nocturnal enuresis in children. Sleep Breath. 2011;15(2):221-227.

52. Esposito M, Gallai B, Parisi L, et al. Primary nocturnal enuresis as a risk factor for sleep disorders: an observational questionnaire-based multicenter study. Neuropsychiatr Dis Treat. 2013;9:437-443.

53. Esposito M, Gimigliano F, Ruberto M, et al. Psychomotor approach in children affected by nonretentive fecal soiling (FNRFS): a new rehabilitative purpose. Neuropsychiatr Dis Treat. 2013;9:1433-1441.

54. Esposito M, Carotenuto M, Roccella M. Primary nocturnal enuresis and learning disability. Minerva Pediatr. 2011;63(2):99-104.

55. Esposito M, Gallai B, Parisi L, et al. Visuomotor competencies and primary monosymptomatic nocturnal enuresis in prepubertal aged children. Neuropsychiatr Dis Treat. 2013;9:921-926.

56. Coppola G, Auricchio G, Federico R, et al. Lamotrigine versus valproic acid as first-line monotherapy in newly diagnosed typical absence seizures: an open-label, randomized, parallel-group study. Epilepsia. 2004;45(9):1049-1053

57. Capovilla G, Beccaria F, Montagnini A, et al. Short-term nonhormonal and nonsteroid treatment in West syndrome. Epilepsia. 2003;44(8):1085-1088. Erratum in: Epilepsia. 2004;45(7):887.

58. Coppola G, Licciardi F, Sciscio N, et al. Lamotrigine as first-line drug in childhood absence epilepsy: a clinical and neurophysiological study. Brain Dev. 2004;26(1):26-29.

59. Bracken BA. Multidimensional Self-Concept Scale Examiner's Manual. Austin, TX: PRO-ED; 1992.

60. Beatrice V, Bracken BA. Test Multidimensionale dell'Autostima. Edizione: Edizioni Erickson, 1993.

61. World Medical Association. World Medical Association Declaration of Helsinki: ethical principles for medical research involving human subjects, 2008 Available from: http://www.wma.net/ en/30publications/10policies/b3/. Accessed April 25, 2013.

62. Perillo L, Esposito M, Contiello M, et al. Occlusal traits in developmental dyslexia: a preliminary study. Neuropsychiatr Dis Treat. 2013;9: 1231-1237.

63. Showkatbakhsh R, Castaldo MI, Jamilian A, et al. Treatment effects of R-appliance and Fränkel-2 in class II division 1 malocclusions. Eur $J$ Paediatr Dent. 2013;14(1):17-22.

64. Perillo L, Padricelli G, Isola G, et al. Class II malocclusion division 1: a new classification method by cephalometric analysis. Eur J Paediatr Dent. 2012;13(3):192-196.

65. Ciavarella D, Monsurrò A, Padricelli G, et al. Unilateral posterior crossbite in adolescents: surface electromyographic evaluation. Eur $J$ Paediatr Dent. 2012;13(1):25-28

66. World Health Organization. Oral health care systems. An international collaborative study. Geneva, Switzerland: WHO; 1985.

67. Hzawawi K, Amalki G, SAl-Zahrani M, Alkhiary YM. Effect of lip position and gingival display on smile and esthetics as perceived by college students with different educational backgrounds. Clin Cosmet Investig Dent. 2013;5:77-80.

68. Giddon DB. Orthodontic applications of psychological and perceptual studies of facial esthetics. Semin Orthod. 1995;1(2):82-93.

69. Shaw WC, O'Brien KD, Richmond S, Brook PH. Quality control in orthodontics: risk benefit appraisal in orthodontics. $\mathrm{Br}$ Dent $J$. 1991;170:33-37.

70. Arndt EM, Travis F, Lefebvre A, Niec A, Munro IR. Beauty and the eye of the beholder: social consequences and personal adjustment for facial patients. Br J Plast Surg. 1986;39:81-84.

71. Fillingim RB, Sinha PK. An introduction to psychologic factors in orthodontic treatment: theoretical and methodological issues. Semin Orthod. 2000;6(4):209-213.

72. Jenny J. A social perspective of dentofacial esthetics and orthognathic surgery. Angle Orthod. 1975;54(1):18-35.

73. Birkeland K, Katle A, Lovgreen S, Boe OE, Wisth PJ. A longitudinal study among 11- and 15-year-olds and their parents on factors influencing the decision about orthodontic treatment. J Orofacial Orthop. 1999;60(5):292-307. 
74. Burden DJ, Pine CM. Self-perception of malocclusion among adolescents. Community Dent Health. 1995;12(2):89-92.

75. Shaw WC. The influence of children's dentofacial appearance on their social attractiveness as judged by peers and lay adults. Am J Orthod. 1980;79(4):399-415.

76. Baldwin DC. Appearance and aesthetic in oral health. Community Dent Oral Epidemiol. 1980;8(5):244-256.

77. Trulsson U, Strandmark M, Mohlin B, et al. A qualitative study of teenagers' decisions to undergo orthodontic treatment with fixed appliance. J Orthod. 2002;29(3):197-204.

78. Peres SH, Goya S, Cortellazzi KL, et al. Self-perception and malocclusion and their relation to oral appearance and function. Cien Saude Colet. 2011;16(10):4059-4066.

79. Cross JF, Cross J. Age, sex, race and the perception of facial beauty. Dev Psychol. 1971;5:433-439.
80. Linn EL. Social meanings of dental appearance. J Health Hum Behav. 1966;7:289-295.

81. Berscheid E, Walster E, Bohrnstedt G. Body image. Psychol Today. 1973;7:119-131.

82. Bellot-Arcís C, Montiel-Company JM, Almerich-Silla JM. Psychosocial impact of malocclusion in Spanish adolescents. Korean J Orthod. 2013;43(4):193-200.

83. Jáuregui Lobera I, Bolaños Ríos P. Body image quality of life in eating disorders. Patient Prefer Adherence. 2011;5:109-116.

84. Hunt O, Hepper P, Johnston C, et al. Professional perceptions of the benefits of orthodontic treatment. Eur J Orthod. 2001;23:315-323.

85. Cunningham SJ, Hunt NP. Quality of life and its importance in orthodontics. J Orthod. 2001;28:152-158.

\section{Publish your work in this journal}

Patient Preference and Adherence is an international, peer-reviewed, open access journal focusing on the growing importance of patient preference and adherence throughout the therapeutic continuum. Patient satisfaction, acceptability, quality of life, compliance, persistence and their role in developing new therapeutic modalities and compounds to optimize clinical outcomes for existing disease states are major areas of interest. This journal has been accepted for indexing on PubMed Central. The manuscript management system is completely online and includes a very quick and fair peer-review system. Visit http://www.dovepress.com/ testimonials.php to read real quotes from published authors.

Submit your manuscript here: http://www.dovepress.com/patient-preference-and-adherence-journal 